\title{
Effect of Oils Categories on the Distribution of Polycyclic Aromatic Hydrocarbons and Derivatives in the Environment
}

\author{
Pranudda Pimsee, Caroline Sablayrolles, Mireille Montrejaud-Vignoles, Julien Guyomarch, Nicolas \\ Lesage, and Pascale De Caro
}

\begin{abstract}
Context and objective: The Migr'Hycar research project was initiated to provide decisional tools for risks connected to oil spill drifts in continental waters. This paper focuses on the distribution of polycyclic aromatic hydrocarbons (PAHs) from oils in water, air and oil slicks.

Material and methods: Six petroleum oils covering a representative range of commercially available products were tested. Dynamic tests at laboratory scale were performed to study 41 PAHs and derivates, among them 16 EPA priority pollutants. Water soluble fraction protocol, stir bar sorptive extraction (SBSE) and high performance gas chromatography mass spectrometry (HPGC-MS) was used. Limit of quantification were lower than 1 ng. $\mathrm{L}^{-1}$ for each compounds.

Results: A large variation in composition of the water soluble fraction depending on oil type and mixing time has been highlighted. Results have shown that evaporation is the primary mechanism of PAHs loss from spilled oil. The subsequent fate of hydrocarbons deposited in surface water is further influenced by volatilisation behaviour because of possible slick loss to the atmosphere. The water soluble fraction remains very low and is dominated by low molecular weight PAHS (e.g. naphthalenes).
\end{abstract}

Index Terms-Monitoring, water soluble fraction, PAHs, Sorptive Bar Solid Extraction.

\section{INTRODUCTION}

The application of the European Water Framework Directive [1] and the monitoring obligation on water quality for human consumption and industrial activities has created a need for water quality evaluation and monitoring systems. An evaluation of industrial reject oils (from all industries) led to around 600 tonnes discharged in 2002 in France [2]. Among the accidents identified, we found manipulation errors, accidental leakage of household or industrial tanks, petrol station leakage, wastewater treatment plant overflows, truck accident, fire and deliberate or accidental discharges of

Manuscript received December 2, 2012; revised December 24, 2012.This work was supported by the French Government in the framework of the Research National Agency “ANR PRECODD” program.

P. Pimsee, C. Sablayrolles, P. De Caro, and M. Montréjaud-Vignoles are with Université de Toulouse; INP; LCA (Laboratoire de Chimie Agro-Industrielle); ENSIACET, 4 Allées Emile Monso, F-31029 Toulouse, France and INRA; LCA (Laboratoire de Chimie Agro-Industrielle), F-31029 Toulouse, France (e-mail : pranudda.pimsee@ensiacet.fr; caroline.sablayrolles@ensiacet.fr; pascale.decaro@ensiacet.fr; mireille.vignoles@ensiacet.fr).

J. Guyomarch is with the CEDRE 715, Rue Alain Colas/CS 41836, 29218 Brest Cedex 2, France (e-mail: Julien.Guyomarch@cedre.fr).

N. Lesage is with TOTAL Petrochemicals France, PERL, RN117 BP 47, F-64170 Lacq, France (e-mail: nicolas.lesage@total.com). river boats

The Migr'Hycar research project (www.migrhycar.com) was initiated to provide decisional tools, and satisfy operational needs, for risks connected to oil spill drifts in continental waters (rivers, lakes, estuaries). These tools aim to serve in the decision-making process once oil spill pollution occurs and/or as reference tools to study scenarios of potential impacts of pollutions on a given site. Within the framework of the Migr'Hycar project, experiments on situations under controlled conditions were conducted in order to evaluate the dissolved, floating and evaporated oil fractions. The water soluble fraction protocol is of special interest because such components dissolved (e.g. naphthalenes, phenanthrenes and dibenzothiophenes) from an oil slick are known to have a high bio-availability to marine organisms, and therefore have a potential to cause toxic effects [3]. Indeed, polycyclic aromatic hydrocarbons (PAHs) are classified as priority hazardous substances and as priority substances by the European Union (Decision 2455/2001/EC). The objectives of the studies were (1) the monitoring of the PAHs in the three compartments (air, water and oil slicks) as a function of the time and (2) the measuring of the studied compounds on final equilibrium. The mass balance was established by quantifying compounds in at least two of the three compartments.

\section{MATERIAL AND METHODS}

\section{A. Material and reagents}

Glassware was cleaned carefully with water, Milli-Q water and acetone HPLC grade. Methanol Ultra LC-MS grade was purchased by Carl Roth (France).

The solutions were prepared from certified reference material purchased from LGC Standards (Molsheim, France) as regards semi-volatile compounds: CUS 9305, which contains 21 PAHs (naphthalene, benzothiophene, biphenyl, acenaphtylene, acenaphtene, fluorine, phenanthrene, anthracene, dibenzothiophene, fluoranthene, pyrene, benzo[a]anthracene, chrysene, benzo[b]fluoranthene, benzo[k]fluoranthene, benzo[e]pyrene, benzo[a]pyrene, perylene, indeno[1,2,3-cd]pyrene, dibenz[a,h]anthracene and benzo[g,h,i]perylene) at the concentration of $1 \mu \mathrm{g} / \mathrm{mL}$ in methanol, and CUS 9207, which contains the corresponding internal standards: Naphthalene $\mathrm{d}_{8}$, Biphenyl $\mathrm{d}_{10}$, Phenanthrene $d_{10}$, Chrysene $d_{12}$ and Benzo[a]pyrene $d_{12}$ at the concentration of $1 \mu \mathrm{g} / \mathrm{mL}$ in acetone. All the calibrations 
curves were obtained by extracting and analyzing water samples spiked with target molecules and corresponding internal standards.

The calibration solutions were prepared by dilution of a PAHs mix solution in $100 \mathrm{~mL}$ Milli-Q water leading to 8 solutions: blank, 0.5 ng. $\mathrm{L}^{-1}, 1 \mathrm{ng} . \mathrm{L}^{-1}, 5 \mathrm{ng} . \mathrm{L}^{-1}, 10 \mathrm{ng} . \mathrm{L}^{-1}, 100$ ng. $\mathrm{L}^{-1}, 500$ ng. $\mathrm{L}^{-1}, 1000 \mathrm{ng} . \mathrm{L}^{-1}$. The extraction standard solution was prepared while diluting $1 \mathrm{~mL}$ of a The extraction standard solution was prepared while diluting 1 $\mathrm{mL}$ of a deuterated PAHs mix solution in $1 \mathrm{~L}$ of methanol (ROTISOLV $\geq 99.98 \%$ Ultra LC-MS by Carl Roth). The standard solutions were stored in amber glass bottles at + $4^{\circ} \mathrm{C}$.

\section{B. Oils studied}

Six different oils, supplied by TOTAL, were studied: Heavy fuel, Domestic fuel, Jet A1, Gasoline (SP98), Gasoline (SP95-E10) and Diesel fuel. They were selected because of their common use and their possible involvement in freshwater oil spills. The oil storage was performed at $+4^{\circ} \mathrm{C}$. Before use, light oils were conserved at room temperature during $12 \mathrm{~h}$. The use of heavy oils was made after a reheat at $70^{\circ} \mathrm{C}$ during $1 \mathrm{~h}$. Physical and chemical properties of oils are described in Table I.

TABLE I: DESCRIPTION OF THE OILS USED AND THEIR MAIN PROPERTIES

\begin{tabular}{|c|c|c|c|c|c|}
\hline Oils & $\begin{array}{l}\text { Physical } \\
\text { State }\end{array}$ & Color & $\begin{array}{l}\text { Density } \\
\left(\mathrm{kg} / \mathrm{m}^{3}\right. \\
\text { at } \\
\left.15^{\circ} \mathrm{C}\right) \\
\end{array}$ & $\begin{array}{l}\text { Octanol-water } \\
\text { partition } \\
\text { coefficient }\end{array}$ & Viscosity \\
\hline $\begin{array}{l}\text { Heavy } \\
\text { fuel }\end{array}$ & $\begin{array}{l}\text { Viscous } \\
\text { liquid at } \\
20^{\circ} \mathrm{C}\end{array}$ & $\begin{array}{l}\text { Brown/Green. } \\
\text { Dark } \\
\text { brown/Black }\end{array}$ & $\begin{array}{l}920- \\
1060\end{array}$ & $\begin{array}{l}2.7 \leq \log \\
\text { Kow } \leq 6\end{array}$ & $\begin{array}{l}>9.5 \\
\mathrm{~mm}^{2} / \mathrm{s} \text { at } \\
20^{\circ} \mathrm{C} \\
<40 \\
\mathrm{~mm}^{2} / \mathrm{s} \text { at } \\
100^{\circ} \mathrm{C}\end{array}$ \\
\hline $\begin{array}{l}\text { Domestic } \\
\text { fuel }\end{array}$ & $\begin{array}{l}\text { Clear } \\
\text { liquid at } \\
20^{\circ} \mathrm{C} \\
\end{array}$ & Characteristic & $\begin{array}{l}820- \\
860\end{array}$ & $\begin{array}{l}3.9 \leq \log \\
\text { Kow } \leq 6\end{array}$ & $\begin{array}{l}<7 \\
\mathrm{~mm}^{2} / \mathrm{s} \text { at } \\
40^{\circ} \mathrm{C} \\
\end{array}$ \\
\hline Jet A1 & Liquid & $\begin{array}{l}\text { Colorless to } \\
\text { pale yellow }\end{array}$ & $\begin{array}{l}775- \\
840\end{array}$ & $\begin{array}{l}3.3 \leq \log \\
\text { Kow } \leq 6\end{array}$ & $\begin{array}{l}<7 \\
\mathrm{~mm}^{2} / \mathrm{s} \text { at } \\
40^{\circ} \mathrm{C}\end{array}$ \\
\hline $\begin{array}{l}\text { Gasoline } \\
\text { SP98 }\end{array}$ & $\begin{array}{l}\text { Clear } \\
\text { liquid at } \\
20^{\circ} \mathrm{C}\end{array}$ & Pale yellow & $\begin{array}{l}720- \\
775\end{array}$ & $\begin{array}{l}2.1 \leq \log \\
\text { Kow } \leq 6\end{array}$ & $\begin{array}{l}0.5-0.75 \\
\mathrm{~mm}^{2} / \mathrm{s} \text { at } \\
20^{\circ} \mathrm{C}\end{array}$ \\
\hline $\begin{array}{l}\text { Gasoline } \\
\text { SP95-E10 }\end{array}$ & $\begin{array}{l}\text { Clear } \\
\text { liquid at } \\
20^{\circ} \mathrm{C} \\
\end{array}$ & Pale yellow & $\begin{array}{l}720- \\
775\end{array}$ & $\begin{array}{l}2.1 \leq \log \\
\text { Kow } \leq 6\end{array}$ & $\begin{array}{l}<1 \\
\mathrm{~mm}^{2} / \mathrm{s} \text { at } \\
40^{\circ} \mathrm{C} \\
\end{array}$ \\
\hline $\begin{array}{l}\text { Diesel } \\
\text { fuel }\end{array}$ & $\begin{array}{l}\text { Liquid } \\
\text { at } 20^{\circ} \mathrm{C}\end{array}$ & Yellow & $\begin{array}{l}820- \\
845\end{array}$ & $\begin{array}{l}3.9 \leq \log \\
\text { Kow } \leq 6\end{array}$ & $\begin{array}{l}<7 \\
\mathrm{~mm}^{2} / \mathrm{s} \text { at } \\
40^{\circ} \mathrm{C}\end{array}$ \\
\hline
\end{tabular}

\section{Water Soluble Fraction}

Water-soluble fraction protocol was performed in darkness at $20^{\circ} \mathrm{C}$. $2000 \mathrm{~g}$ of Milli-Q water were introduced in a 3L glass beaker. $200 \mathrm{mg}$ of oil were deposed on water surface, conducing to about a $10 \%$ surface ratio. A gentle stirring without vortex was ensured to allow the diffusion of

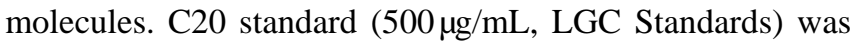
added in order to evaluate evaporation part. Mixing times were fixed to $1 \mathrm{~h}, 3 \mathrm{~h}, 6 \mathrm{~h}, 10 \mathrm{~h}, 24 \mathrm{~h}$ and $48 \mathrm{~h}$. First, totality of the slick was sampled was sampled with a $100 \mathrm{~mL}$ volumetric pipette after a given time of exposure to the oil. The sample was separated in a separating funnel in order to recover the oil fraction. Separating funnel was rinsed with $10 \mathrm{~mL}$ of dichloromethane. An aliquot of $2 \mathrm{~mL}$ was then sampled and stored at $+4^{\circ} \mathrm{C}$ for GC/MS analysis. Then, the soluble fraction was sampled with a $100 \mathrm{~mL}$ volumetric pipette in order to take a water sample free from oil after a given time of exposure to the oil. This fraction was extracted by sorptive bar solvent extraction (SBSE).

\section{PAHs analysis}

This analytical method was used to analyze the 15 PAHs from the EPA priority pollutants list, plus 26 PAHs derivates which are more soluble compounds.

1) PAHs in water (soluble fraction): SBSE-TD-GC-MS

$100 \mathrm{~mL}$ water samples were added with $10 \mathrm{~mL}$ of methanol containing the 5 deuterated internals standards at the concentration of $1 \mathrm{ng} / \mathrm{mL}$ (final concentration of $100 \mathrm{ng} / \mathrm{L}$ relatively to water). Stir bars (Twister ${ }^{\circledR} 20 \mathrm{~mm}$ x $0.5 \mathrm{~mm}$ PDMS by Gerstel) were then added to the water samples and stirred at $700 \mathrm{rpm}$ for two hours. Stir bars were then recovered by using tweezers, dried over plot paper and stored in a vial at $+4{ }^{\circ} \mathrm{C}$ for subsequent GC/MS analysis [4].

The analyses were performed using a Thermal Desorption Unit combined with a Cooled Injection System from Gerstel (Mülheim an der Ruhr, Germany) mounted on a 7890 Agilent GC system coupled to an Agilent 5975 mass spectrometrer (Agilent Technologies, Little Falls, DE, USA). The analytical system was equipped with an automated sampler MPS2 (Gerstel). Desorption was achieved at $300{ }^{\circ} \mathrm{C}$ for 10 minutes under an helium flow of $50 \mathrm{~mL} / \mathrm{min}$ in the splitless mode and with a transfer line maintained at $300{ }^{\circ} \mathrm{C}$. The desorbed compounds were cryofocused in a cooled injection system (CIS-4, Gerstel) at $10^{\circ} \mathrm{C}$ and then transferred to the HP-5MS column $(30 \mathrm{~m} \times 0.25 \mathrm{~mm}$ i.d. $\times 0.25 \mu \mathrm{m}$ film thickness, constant helium flow of $1 \mathrm{~mL} / \mathrm{min}$ ) by a rapid increase of the CIS temperature (from $10^{\circ} \mathrm{C}$ to $300^{\circ} \mathrm{C}$ at $12^{\circ} \mathrm{C} / \mathrm{s}$ ). For the analysis of $\mathrm{PAHs}$, the oven program of temperature was: from $50^{\circ} \mathrm{C}(1 \mathrm{~min})$ to $150^{\circ} \mathrm{C}$ at $10^{\circ} \mathrm{C} / \mathrm{min}$, and then to $320^{\circ} \mathrm{C}(5 \mathrm{~min})$ at $5^{\circ} \mathrm{C} / \mathrm{min}$. The mass spectrometer was operated in Selected Ion Monitoring (SIM) with a minimum of 2 cycles/s. The quantification was performed by using the molecular ion of each PAH. The target molecules were quantified relatively to the deuterated PAHs (internal standards) using a calibration curve (from 0.1ng/L to $100 \mathrm{ng} / \mathrm{L}$ ) with regression coefficient $>0.99$. Limit of quantification were lower than $1 \mathrm{ng} . \mathrm{L}^{-1}$ for each compounds.

2) PAHs in oils (initial and slick fraction): $G C-M S$

The analysis was performed as described previously except the injection technique. The split/splitless injector was used in the pulse splitless mode (pulse pressure: $15 \mathrm{psi}$, splitless time: $1 \mathrm{~min}$, flow $50 \mathrm{~mL} / \mathrm{min}$ ). The injector temperature was maintained at $300^{\circ} \mathrm{C}$. PAHs were quantified in the oil in their initial state (no weathering) relatively to the deuterated PAHs (internal standards) using a calibration curve (from $0.1 \mathrm{ng} / \mathrm{L}$ to $100 \mathrm{ng} / \mathrm{L}$ ).

A semi-quantitative method was applied to the slick. In this view, the fraction of molecules disappearing from the slick was assessed relatively to a compound or group of compounds present in the slick, sufficiently abundant, poorly volatiles and of low solubility. In the case of products characterized by a residue at $250^{\circ} \mathrm{C}$ higher than $30 \%$, compounds with a molecular weight equal or higher than 
C3-phenanthrenes were chosen. For lighter products (gasoline and kerosene), as no compound meets these requirements, oils were spiked with a linear alkane $(\mathrm{nC} 20)$ at the concentration of $500 \mu \mathrm{g} / \mathrm{mL}$. This method was adopted as the amount of oil sampled at the water surface could not be determined precisely (presence of water). In the case of oils sampled during the experiment at $T_{i}$, the calculation of the target compounds concentrations was performed according equation 1 .

$$
C_{C i / T i}=C_{C i / T 0} \times \frac{A_{C i / T i}}{A_{C i / T 0}} \times \frac{A_{H / T i}}{A_{H / T 0}}
$$

Eq. 1: Calculation of the target PAHs in the floating fraction.

$\left(\mathrm{C}_{\mathrm{Ci} / \mathrm{Ti}}\right.$ : target compound concentration at $\mathrm{Ti} ; \mathrm{C}_{\mathrm{Ci} / \mathrm{T} 0}$ : target compound concentration in initial oil $; \mathrm{A}_{\mathrm{Ci} / \mathrm{Ti}}$ : target compound area at $\mathrm{Ti} ; \mathrm{A}_{\mathrm{Ci} / \mathrm{T} 0}$ : target compound area in initial oil ; $\mathrm{A}_{\mathrm{Hi} / \mathrm{Ti}}$ : reference compound area at $\mathrm{Ti} ; \mathrm{A}_{\mathrm{Hi} / \mathrm{TO}}$ : reference compound area in initial oil)

\section{RESULTS AND INTERPRETATION}

\section{A. Fresh Oil Characterization}

PAHs levels in the initial oils were presented Fig. 1. The characterization has shown that domestic fuel had the highest PAHs content, gasoline (SP95, SP98) the lowest.

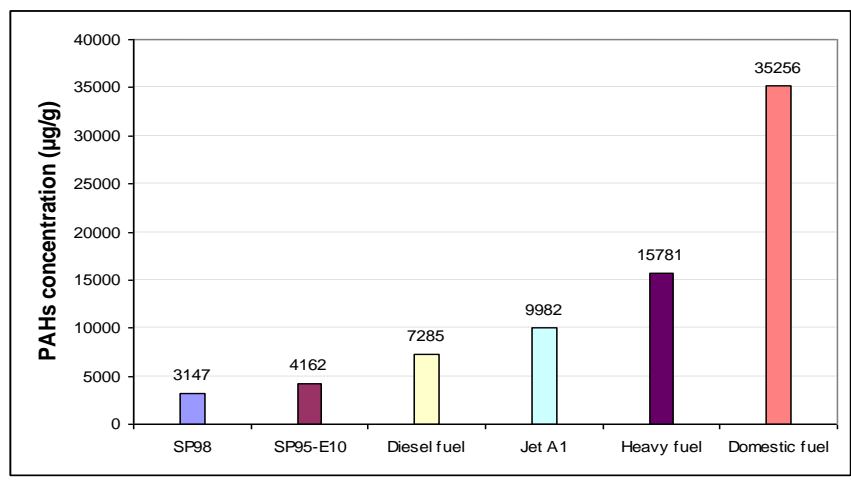

Fig. 1. Initial concentration of the $41 \mathrm{PAHs}$ in oils.

\section{B. Mass Balance of PAHs}

The results are presented based on the sum of the 41 PAHs as a global indicator and the naphthalene level (naphthalene + $\mathrm{C}_{1} \mathrm{C}_{2} \mathrm{C}_{3} \mathrm{C}_{4}$ derivates). The distribution of PAHs from the 6 oils in the 3 compartments (water, air and oil slicks) is shown in Fig. 2. In all cases, at 48 hours contact time, equilibrium was observed corresponding to three phenomenons: dissolution, evaporation and volatilisation (Fig. 3).

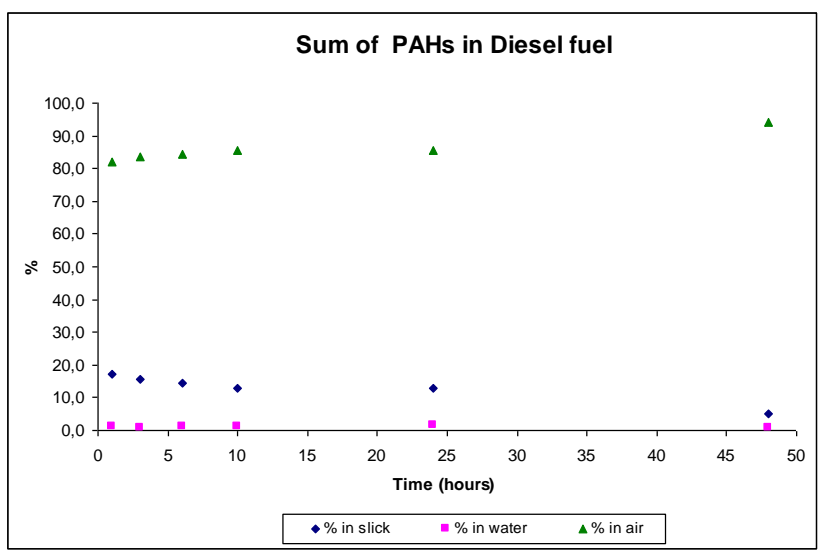

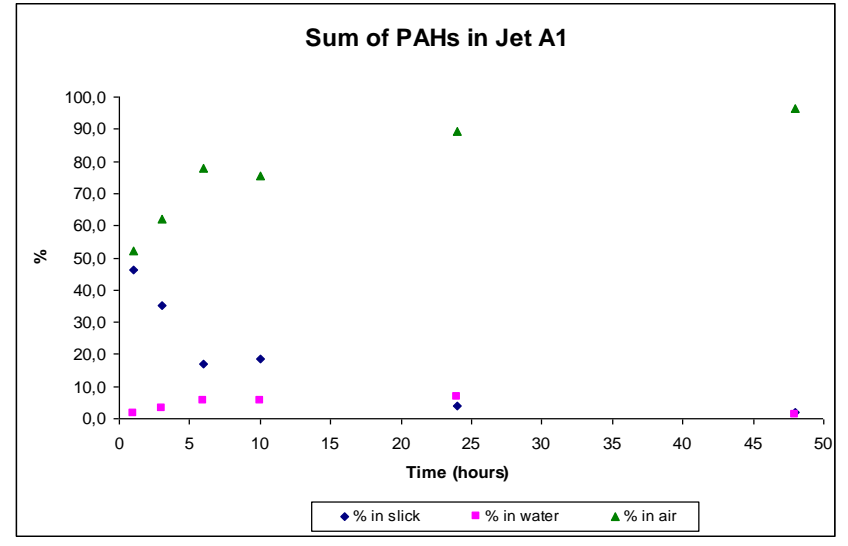
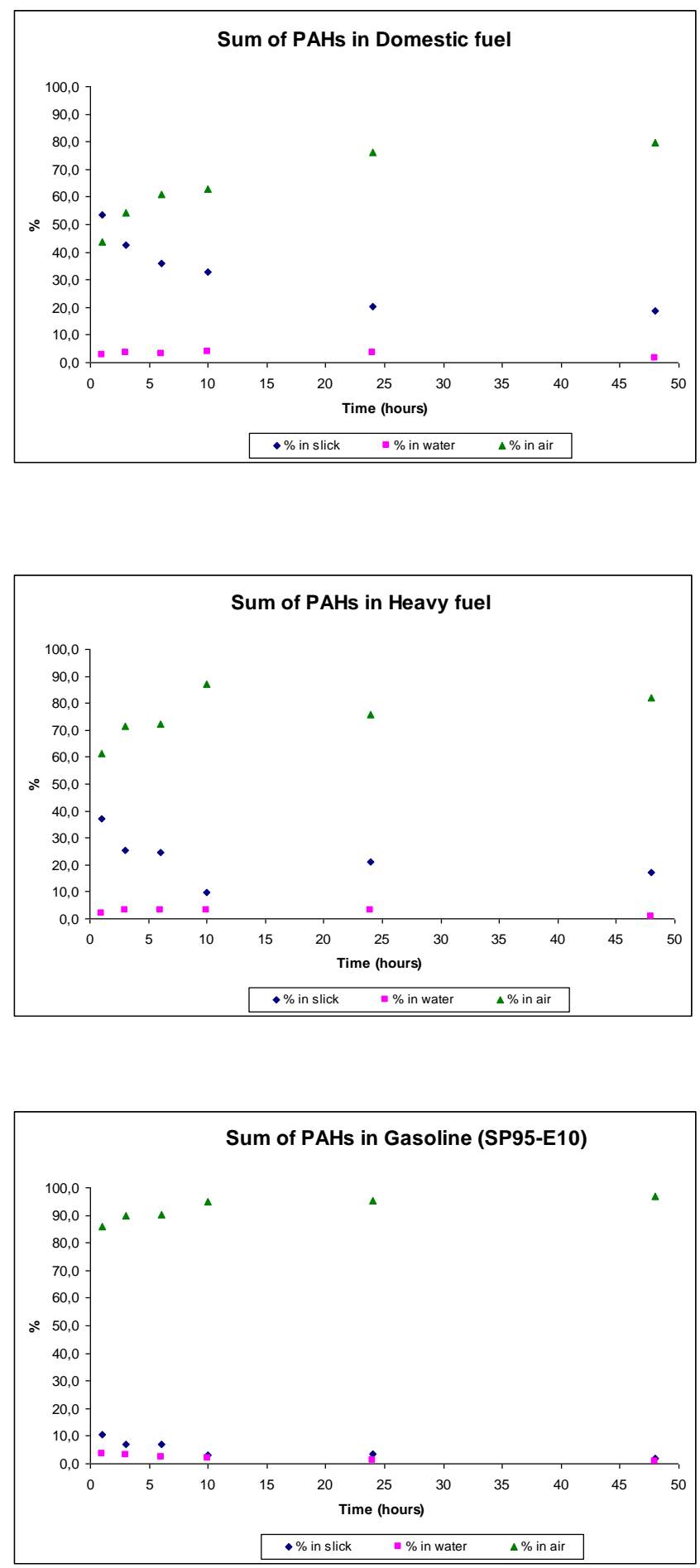


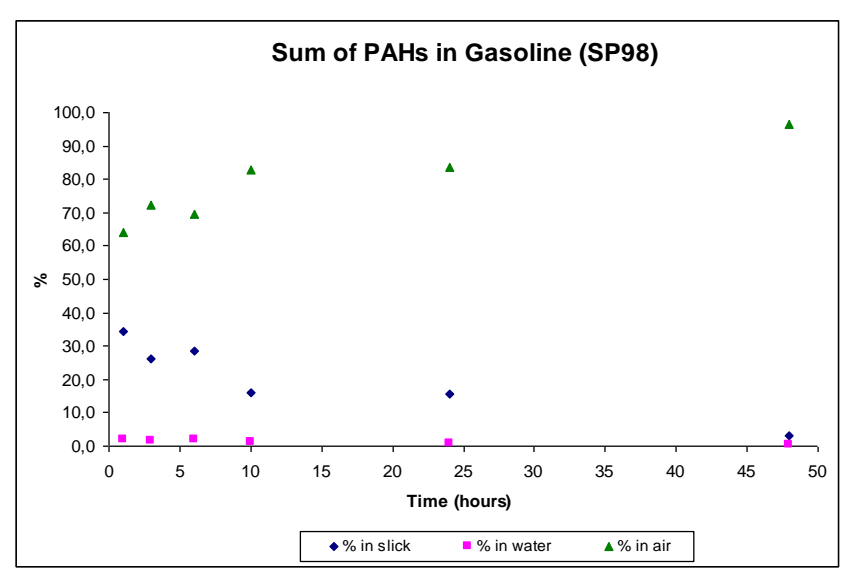

Fig. 2. Distribution of PAHs (\% in air, \% in water and \% in slick) as function of time for the 6 oils studied.

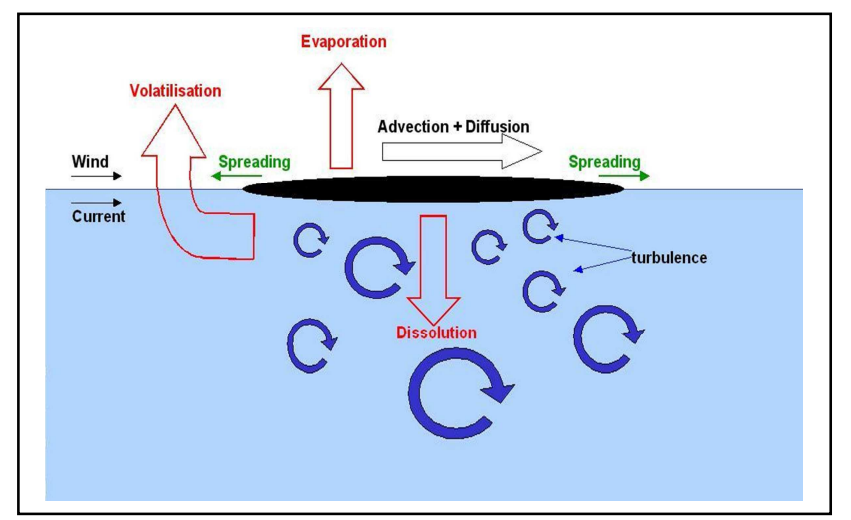

Fig. 3. Distribution of PAHs [8]

\section{1) Water dissolution and solubility}

The oil quantity affected by the dissolution process is lower than $11 \%$ of the initial mass [10]. Due to their physical, chemical properties, only PAHs are assumed to be dissolved in water [9].

Analysing the water soluble fraction, we observed that water solubility of PAHs tends to decrease with increasing molecular weight. Moreover, linear fused PAHs (e.g. naphthtalene and anthracene) also tend to be more soluble than pericondensed structures (e.g. phenanthrene and pyrene) Furthermore, alkyl substitution decreases water solubility of parental PAHs. Naphthalenes are dominating sum of PAHs profile because of their high solubility in water.

\section{2) Volatilisation}

When petroleum products enter surface-water systems, the lighter aliphatic and aromatic hydrocarbons spread out along the surface of water and evaporate. In general, evaporation is the primary mechanism of loss of volatile and semi-volatile compounds of spilled oil. As it is shown in figure 1, evaporation is almost total in the case of gasoline, diesel fuel and kerosene, which are rich in naphthalenes which easily sublimates in the air and presents the highest water solubility in water. For the heavy and domestic fuels, the oil slick remains around $20 \%$. Indeed, these oils contain phenanthrene and chrysene, less volatile and less soluble than naphthalene.

If we measure what is remaining in the silk for SP95-E10, SP98 and kerosene, we observe that no PAHs persist in the silk. Although, for domestic fuel, heavy fuel and diesel fuel, we observe a persistence of phenanthrene compounds (Table
II).

TABLE II: PERSENTATION OF PHENANTHRENES AT 48 HOURS

\begin{tabular}{|l|l|l|l|}
\hline PAHs & Domestic fuel & Heavy fuel & Diesel fuel \\
\hline Phenanthrene & 3.7 & 2.1 & 0.2 \\
\hline $\mathrm{C}_{1}$-Phenanthrene & 6.8 & 4.1 & 0.3 \\
\hline $\mathrm{C}_{2}$-Phenanthrene & 2.6 & 1.9 & 0.2 \\
\hline $\mathrm{C}_{3}$-Phenanthrene & 1.0 & 1.0 & 1.0 \\
\hline$\Sigma$ Phenanthrene & 14.1 & 9.2 & 1.7 \\
\hline
\end{tabular}

The partitioning between air and water is characterized by Henry's law constant $\left(\mathrm{K}_{\mathrm{H}}\right)$. The $\mathrm{K}_{\mathrm{H}}$ implies higher volatility and results from combination of high vapour pressure and high aqueous solubility (Table III). Volatilisation losses from aqueous phase to the atmosphere are also influenced by the aqueous solubility of the compounds.

TABLE III: CALCULATION OF THE TARGET PAHS IN THE FLOATING FRACTION [5]

\begin{tabular}{|l|l|l|l|}
\hline PAHs & $\begin{array}{l}\text { Water Solubility } \\
{[\mathrm{mg} / \mathrm{L}]}\end{array}$ & $\begin{array}{l}\text { Vapor Pressure } \\
{[\mathrm{mmHg} \text { at }} \\
\left.25^{\circ} \mathrm{C}\right]\end{array}$ & $\begin{array}{l}\text { Henry } \\
\text { constant } \\
{[\text { bar at 298K] }}\end{array}$ \\
\hline Naphthalene & 32 & $8.210^{-2}$ & 23.796 \\
\hline Phenanthrene & 1.0 & $6.810^{-4}$ & 1.771 \\
\hline Chrysene & 0.006 & $6.310^{-7}$ & 0.036 \\
\hline
\end{tabular}

\section{3) Ethanol influence}

We can observe that gasoline SP95-E10 presents a reduced oil slick compared to gasoline SP98. Indeed, the addition of ethanol in gasoline increases PAHs solubilisation [6]. But, the decrease of oil slick is also due to the increase of hydrocarbons volatility of which form azeotrops with ethanol [7]. The both phenomena explain the difference between the oil slicks of gasoline, while the soluble fractions remain low.

\section{CONCLUSION}

Within the Migr'Hycar research project, experimentations at laboratory scale were performed to study the behaviour of hydrocarbons when petroleum products enter surface-water systems. This work required the development of an experimental protocol to evaluate the behaviour of PAHs in the 3 compartments. Data were the results of the equilibrium obtained during the distribution of hydrocarbons in the different phases. Six petroleum oils were studied and 41 polycyclic aromatic hydrocarbons and derivates (PAHs) were monitored. The mass balance in the 3 compartments (air, water and slick) was established by quantifying compounds in water and slick.

Results have shown that evaporation is the primary mechanism of PAHs loss from spilled oil. The subsequent fate of hydrocarbons deposited in surface water is further influenced by volatilisation behaviour because of possible slick loss to the atmosphere. The addition of water miscible oxygenated compounds, such as ethanol, to fuels increases the global solubility of PAHs. The water soluble fraction remains very low and is dominated by low molecular weight PAHS (e.g. naphthalenes). In spite of their low solubility, dissolution is an important media exchange process leading to the primary destruction pathway of hydrocarbons in aquatic systems via biodegradation. 


\section{REFERENCES}

[1] EU. Directive 2000/60/EC of 23 October 2000 establishing a framework for Community action in the field of water policy. Off. J. Eur. Comm.. L327. 22.12.2000, 2000.

[2] RNDE (Réseau National des Données sur l'Eau). [Online]. Available: http://www.sandre.eaufrance.fr/, 2002.

[3] J. M. Neff, S. Ostazeski, W. Gardiner, and I. Stejskal, "Effects of weathering on the toxicity of three Australian crude oils and a diesel fuel to marine animals," Environ. Toxicol. Chem. 2000, vol. 19, pp. 1809-1821.

[4] J. Guyomarch and S. Van Ganse, "Determination of Polynuclear Aromatic Hydrocarbons in Seawater following an Experimental Oil Spill by Stir Bar Sorptive Extraction (SBSE) and Thermal Desorption GC-MS," in Proceeding of the $33^{\text {rd }}$ AMOP Technical Seminar on Environmental Contamination and Response, Environment Canada, Ottawa, 2010, pp. 181-187.

[5] D. Mackay, W. Y. Shiu, K. C. Ma, and S. C. Lee, 2006, "Handbook of physical-chemical properties and Environmental Fate For Organic Chemicals," vol. 2, Taylor \& Francis/ CRC Press, Boca Raton.

[6] H. X. Corseuil, B. I. A. Kaipper, and M. Fernandez, "Cosolvency effect in subsurface systems contaminated with petroleum hydrocarbons and ethanol," Water Researc., vol. 38, pp. 1449-1456, 2004 .

[7] Z. Muzicova, M. Pospisil and G. Sebor, "Volatility and phase stability of petrol blends with ethanol," Fuel, vol. 88, pp. 1351-1356, 2009.

[8] C. Goeury and J-M. Hervouet, "A lagrangian/Eulerian oil spill model for continental waters," J. of Hydraulic Research. 2012.

[9] D. Hibbs, J. Gulliver, V. Voller, and Y-F. Chen, "An aqueous concentration model for riverine spills," J. of Hazardous Materials. 1999, vol. 68, pp. 37-53.

[10] C. Sablayrolles, P.Pimsee, P. De Caro, N. Lesage, J. Guyomarch, G. Vilarem, and M. Montréjaud-Vignoles, "Dynamic behavior of polycyclic aromatic hydrocarbons and derivatives alter oils spill in water," Environ. Pollution J. 2012 (to be published).

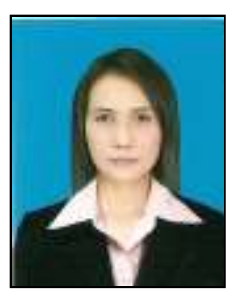

P. Pimsee was born in Thailand in April $28^{\text {th }}$ 1977. She obtained a Master's degree of Education in chemistry, and Bachelor's degree of Education (2ndHons) in Chemistry Sciences at Srinakharinwirot University (Bangkok, Thailand).

She joined the Faculty of Science and Technology, Rajamangala University of Technology Krungthep (Bangkok, Thailand) as Lecturer in the Department of Science and the Chemistry Division. Nowadays, she is performing a phD in the field of environmental chemistry in the Toulouse University, Laboratoire de chimie agro-industrielle, ENSIACET-INP Toulouse, France. The title of her thesis is "Behaviour study of polycyclic aromatic hydrocarbons (PAHs) during oil spill in inland waterways".

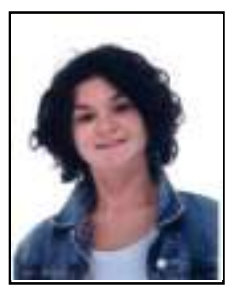

C. Sablayrolles (Toulouse, France, 26/01/1978) was graduated from the National Engineering School of Chemistry of Toulouse (ENSCT, Toulouse, France) in 2001, with a specialization in bio-resources chemistry and technology.

She has made several placements in France and in the Netherlands in research and industrial firms. She was recruited by INPT-ENSIACET (Toulouse, France) in 2007. She is an Assistant Professor specialized in environmental chemistry with particular expertise in analytical chemistry and Life Cycle Assessment of green processes. This specialization involves performing chemical characterizations, as well as developing methods to quantify and identify priority pollutants in the environment.

Dr Sablayrolles is a member of the Society of Environmental Toxicology and Chemistry (SETAC), Chemical Engineering French society (SFGP) and International Water Association (IWA). She has over 10 years' experience of working on industrial projects, National projects and International projects involving the multi-criteria analysis for Sustainability. She has already published 25 scientific publications and one handbook chapter.

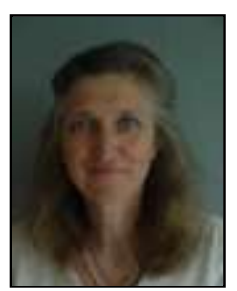

M. Montréjaud-Vignoles is Associate Professor at the National Polytechnic Institute of Toulouse France (INPT). She is doctor of physics Sciences. She is specialized in the behavior of organic and inorganic trace elements susceptible to be toxic for the environment. Three axes are concerned:

The study of the phenomena of transfers water-ground-grass closely linked to the development of analytical methods of trace elements.

- Optimization of the processes of treatment of the polluted aqueous effluents (study of the rainwaters of the City of Toulouse since 1987), the grounds and the by-products of the agro-resources.

- The environmental evaluation such as the Life Cycle Assessment: optimization and objectification of working methodologies by specifying in particular the outlines of the studied systems and the valuation methods of flows and impacts.

She is involved in the scientific life of her establishment where she is elected member of the scientific council. She is also member of IWA, ASTEE...

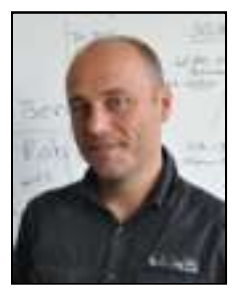

J. Guyomarch (Morlaix, France, 19/07/1974) graduated from the National Engineering School of Chemistry of Rennes (ENSCR, Rennes, France) in 1997 , with a specialization in organic chemistry and biotechnologies.

He has made several placements in France and in $\mathrm{UK}$, in research and industrial laboratories, and joined CEDRE (Brest, France) in 1997 for his military service before being recruited in 1998. He is specialised in studying the behaviour of oils spilt at sea, as well as in the evaluation of different oil spill response techniques. This specialisation involves performing full chemical characterisations, as well as developing methods to quantify and identify oil contamination in the environment and to determine its origin. Alongside his spill expertise, he has been developing various SBSE (Stir Bar Sorptive Extraction) analysis methods since 2005, initially geared towards oil, then progressively towards WFD (Water Framework Directive) target molecules.

M. Guyomarch is a member of the European working group in charge of developing methods to identify the origin of oil contaminations.

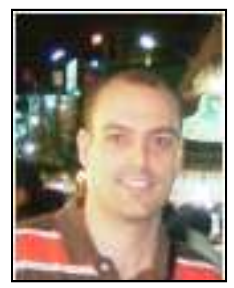

N. Lesage is a chemical engineer (Master degree in Industrial Process Engineering and Master Degree in Chemical Engineering \& Environment) and defended a $\mathrm{PhD}$ in Process and Environmental Engineering. $\mathrm{He}$ is also graduated from the doctoral college of the French Petroleum Institute (IFP). He is the head of the Industrial Effluent Treatment Laboratory of the PERL since 2005. He conducts research, provides technical support and acts as advisor in water treatment for the Total Group. His research is chiefly concerned with the development of water treatment techniques, including separation processes (separation, adsorption, flotation, sedimentation and membranes), chemical oxidation and biological treatment and he is also involved in the assessment of treatment and analytical technologies. He has the role of environmental and water treatment specialist for the Total Group. He is a board member of the "Club Français des Membranes" (French Membrane Club), in the bureau of air and water treatment working group of the SFGP (French Chemical Engineering Society), a member of the European Technical Working Group for the definition of the "best available techniques reference documents" (BREF) 'Common Waste Water and Waste Gas Treatment'. He is contributing to several French and international research programs. He co-directs a number of theses relating to membrane and biological water treatment processes. He is the author or co-author of over 30 publications in international reviews or peer-reviews conference proceedings.

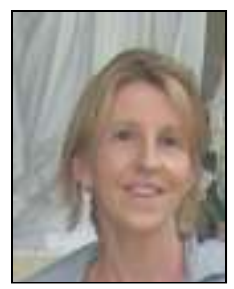

P. De Caro is graduated from the National Engineering School of Chemistry of Toulouse (ENSCT, Toulouse, France) with a specialization in bio-resources chemistry and technology.

She is an associate professor at INPT-ENSIACET in Toulouse (France). She prepared a PhD about the synthesis of biobased polyoxygenated compounds as fuel additives. In the Agro-Industrial Laboratory, her current research area deals with the development of bioproducts from vegetable resources according to clean technologies. She is interested by the whole production chain of these alternative products (synthesis, physical chemical properties and fate) in connection with environmental aspects. 